$\infty$

0

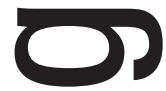

-

ת

1

$\longrightarrow$ 



\title{
MEANDROS NA PRODUÇÃO DO ESPAÇO URBANO: MOBILIDADE, ACESSIBILIDADE E EXCLUSÃO SOCIAL'
}

\author{
MEANDERS IN PRODUCTION OF URBAN SPACE: MOBILITY, ACCESSIBILITY AND SOCIAL EXCLUSION \\ LOS MEANDROS DE LA PRODUCCIÓN EN EL ÁREA URBANA: LA MOVILIDAD, LA ACCESIBILIDAD Y LA \\ EXCLUSIÓN SOCIAL
}

\author{
Marcos Leandro Mondardo - Universidade Estadual de Mato Grosso do Sul \\ marcosmondardo@yahoo.com.br
}

\begin{abstract}
Resumo
Este trabalho tem por objetivo analisar a produção do espaço urbano no modo de produção capitalista. A partir de três elementos, consideramos aqui, metaforicamente, os meandros na produção do espaço urbano, ou seja, a mobilidade, a acessibilidade e a exclusão social buscamos compreender as diferenças na espacialização das relações. Nesse contexto, a produção do espaço urbano ocorre através de objetos e de ações, do trabalho, de idéias e de representações, de modos de vida etc. 0 espaço urbano é produzido, desse modo, através da mobilidade de pessoas e de objetos, de pessoas que levam objetos, de objetos que transformam a mobilidade das pessoas. São relações que interagem no espaço urbano, criando e re-criando através da mobilidade a acessibilidade e propiciando o acesso rápido e eficiente para determinados lugares. Através da produção do espaço diferenciado, a acessibilidade é desigual para as diferentes classes e/ou frações de classes que se movem, que trabalham, que sobrevivem. Essa desigualdade cria exclusão social (ou inclusão precária), em função desses meandros na produção do espaço como a mobilidade, que pode permitir, melhorar e potencializar a acessibilidade. São meandros, são relações sociais que produzem o espaço urbano de maneira diferenciada.
\end{abstract}

Palavras-chaves: Espaço urbano. Produção. Mobilidade. Acessibilidade. Exclusão social.

\begin{abstract}
This work aims to analyze the production of urban space in the capitalist mode of production. From three elements we consider here, metaphorically, the meanders in the production of urban space, ie, mobility, accessibility and social exclusion we understand the differences in spatial relations. In this context, the production of urban space occurs through objects and actions, work, ideas and representations, ways of life etc. Urban space is produced, thus, through the mobility of people and objects, of people that take objects, of objects that transform the mobility of people. Are relationships that interact in the urban re-creating and creating through the accessibility and mobility by providing fast and efficient access to certain places. Through the production of space differential accessibility is uneven for different classes and/or fractions of classes that move, that work, which survive. This inequality creates social exclusion (or inclusion precarious), depending on the intricacies of the production area such as mobility, which can enable, improve and increase accessibility. San meanders, are social relations that produce the urban space in a different way.
\end{abstract}

Key-words: Urban space. Production. Mobility. Accessibility. Social exclusion.

\section{Resumen}

Este trabajo tiene como objetivo analizar la producción del espacio urbano en el modo de producción capitalista. A partir de tres elementos que consideramos aquí, metafóricamente, los meandros de la producción de espacio urbano, es decir, la movilidad, la accesibilidad y la exclusión social entendemos las diferencias en las relaciones

\begin{tabular}{|l|c|c|c|c|c|c|}
\hline Boletim Goiano de Geografia & Goiânia - Goiás - Brasil & v. 29 & n. 1 & p. 57-72 & jan. / jun. & 2009 \\
\hline
\end{tabular}


espaciales. En este contexto, la producción de espacio urbano se produce a través de objetos y acciones, el trabajo, las ideas y representaciones, las formas de vida, etc. Espacio urbano se produce, por lo tanto, a través de la movilidad de personas y objetos, de las personas que tengan objetos, de los objetos que transforman la movilidad de las personas. Son las relaciones que interactúan en el medio urbano y re-crear a través de la creación de la accesibilidad y la movilidad mediante el suministro rápido y eficaz acceso a determinados lugares. A través de la producción del espacio diferenciado de accesibilidad es desigual para las distintas clases y/o fracciones de clases que se mueven, que el trabajo, que sobreviven. Esta desigualdad genera la exclusión social (inclusión o precaria), dependiendo de la complejidad de la zona de producción como la movilidad, que permita, mejorar y aumentar la accesibilidad. San meandros, son las relaciones sociales que producen el espacio urbano de una manera diferente.

Palabras clave: Espacio urbano. La producción. La movilidad. La accesibilidad. La exclusión social.

\section{Introdução}

A produção do espaço urbano é constituída por inúmeros fatores que se processam no modo de produção capitalista. São aqueles que se relacionam e que atribuem singularidades às formas-conteúdos urbanas. São movimentos de pessoas, são movimentos de objetos, são ações e objetos, são relações entre pessoas em movimento, sujeitos que se movimentam para o trabalho, lazer, consumo dentre outros. A produção do espaço urbano é, portanto, composta por um amálgama de relações solidárias e contraditórias entre pessoas e objetos.

Desse modo, o objetivo desse trabalho é analisar os meandros na produção do espaço urbano, aqui, considerados como, a mobilidade, a acessibilidade e a exclusão social. Em especial, buscamos compreender como esses elementos interagem e se inter-relacionam na produção do e no espaço urbano. Nosso intuito consiste em analisar esses elementos, vislumbrando demonstrar as diferenciações espaciais na produção do espaço urbano.

Assim, estruturamos nosso trabalho da seguinte maneira: na primeira parte, analisa-se a produção do espaço urbano; na segunda parte, discute-se os elementos conceituais que estamos considerando meandros da produção do espaço, ou seja, a "sinuosidade" e/ou a singularidade na/da produção do espaço como, a mobilidade, a acessibilidade e a exclusão social; por fim, apresentamos nossas considerações sobre esses elementos em relação à produção do espaço urbano.

\section{O invólucro na produção do espaço urbano}

A expressão "produção do espaço", provavelmente cunhada por Lefebvre no final dos anos 1960, visa responder aos processos de reprodução das 
relações capitalistas de produção. O espaço para Lefebvre (1974) consiste no lugar onde as relações capitalistas se reproduzem e se localizam com todas as suas manifestações de conflitos e contradições.

Lefebvre (1974) ainda distingue, no processo de produção do espaço, apropriação de dominação ("possessão", "propriedade”). O primeiro sendo um processo muito mais simbólico, carregado das marcas do "vivido", do valor de uso, e o segundo, mais concreto, funcional e vinculado ao valor de troca. Segundo o autor, "o uso reaparece em acentuado conflito com a troca no espaço, pois ele implica ‘apropriação' e não 'propriedade’. Ora, a própria apropriação implica tempo e tempos, um ritmo ou ritmos, símbolos e uma prática” (p. 411). Logo, "tanto mais o espaço é funcionalizado, tanto mais ele é dominado pelos 'agentes' que o manipulam tornando-o unifuncional, menos ele se presta à apropriação. Por quê? Porque ele se coloca fora do tempo vivido, aquele dos usuários, tempo diverso e complexo" (LEFEBVRE, 1974, p.412).

Para Santos (1997, p. 38), a ideia central da interpretação da produção do espaço situa-se na combinação simultânea entre a forma, a estrutura e a função. Isso porque, "os movimentos da totalidade social modificando as relações entre os componentes da sociedade, alteram processos e incitam funções”. Essa totalidade social, afirma Santos(1997), pressupõe a existência de um movimento dialético da estrutura que opera sobre as formas e funções, fazendo com que os lugares tornem-se combinações de variáveis que diferenciam se ao longo do tempo.

A diferenciação entre as variáveis resulta tanto da periodização histórica, pois atravessam épocas posteriores ao seu surgimento e convivem com variáveis novas, quanto de suas formas de espacialização, isto é, do seu lugar de origem e de sua difusão territorial. Nesse sentido, é a ideia de movimento da totalidade no tempo e no espaço que fundamenta a concepção de que o espaço é produzido no e pelo movimento da totalidade social. Consiste, portanto, em uma "geografização" do movimento estrutural da sociedade que se traduz espacialmente em novas formas e funções e estas, ao se combinarem para atender as necessidades geradas pelos "efeitos" de reestruturação dos processos de organização das relações sociais, produzem o espaço. Neste caso, a ideiade produção do espaço torna-se prisioneira de sua conotação técnica e econômica e adquire a noção de fabricação repetitiva de formas e geração de movimentos.

Em A Natureza do Espaço, Santos (2004, p. 21) tem como definição de espaço um "conjunto indissociável de sistemas de objetos e sistema de 
ações”. Esta noção permite, segundo o autor, reconhecer, entre outros conceitos, o de produção do espaço e de rugosidades. Assim, quando se fala em produção do espaço deve-se, primeiramente, entender que os conceitos que procuram explicá-la se organizam a partir de uma lógica interpretativa correspondente aos objetivos traçados pelo sujeito. Para esclarecer essa questão, vamos partir do conceito de produção. Na análise da produção do espaço, a ideia de produção está ligada ao conceito marxista de trabalho e às noções de transformação e mudança. A "produção" implica também em organização do trabalho e dos meios necessários para a sua realização enquanto produção de valor. Logo, os meios necessários ao trabalho constituem-se, também, em trabalho. Pode-se pensar que o espaço produzido é produto do trabalho, isto é, de uma organização do trabalho que se materializa em formas espaciais. A "produção" significa, então, "trabalho morto" e organização.

Assim, a produção do espaço, para Santos (2004), é produção de objetos que articulam e organizam, em suas funções específicas, intercâmbios sociais que envolvem o trabalho e a produção. O espaço seria, neste caso, a materialidade e a mediação entre os sistemas de produção, de controle e reprodução do trabalho em sua dimensão técnica e material. Em poucas palavras, o espaço seria um sistema de sistemas ou, como afirma Santos (2004, p. 103), "sistemas de objetos" e "sistemas de ações". No entanto, a produção do espaço urbano também é definida por outros elementos que vão além do elemento econômico e do trabalho na análise, como por exemplo, a ideologia, o "estilo de vida", as ideias, as formas de morar:

O espaço urbano é também definido pela produção e difusão de ideologias, o que inclui a produção e a conseqüente difusão de um 'estilo de vida', valores, gostos, acontecimentos, experiências, interesses, necessidades, significados, idéias, novas formas de morar, ou num sentido mais amplo, marcado pela composição de um texto imaginário, o que favorece a diferenciação, o isolamento e o primado do espaço privado. Instaura-se um processo contraditório entre necessidade de aglomerar (imposta pela cidade) e, ao mesmo tempo, de se afastar/ isolar (CALIXTO, 2001, p. 80).

Desse modo, a produção do espaço urbano perpassa pelo cotidiano dos sujeitos que são e produzem o espaço urbano. O cotidiano é elemento fundamental na construção das cidades e nas formas idiossincráticas de produção do espaço urbano, como considera também Carlos (2004). Corrêa (1995, p. 26), por sua vez, afirma que "o espaço é concebido como lócus da 
reprodução das relações sociais de produção, isto é, reprodução da sociedade”, pois, como afirma Lefebvre (1999a, p. 39), “quem diz 'produção' diz também 'reprodução', ao mesmo tempo, física e social: reprodução de um modo de vida”. Ou seja, enquanto produção material, se (re)produz também um modo de vida, que comporta ideias, sonhos, desejos etc. Desse modo, o espaço geográfico é a morada do homem e é multidimensional (CORRÊA, 1995, p. 44).

Portanto, que a produção do espaço não se limitaria apenas à produção física do capital, mas também, a produção da(s) forma (s) de vida da (s) pessoa (s), com suas ideias e representações, pois "a produção em sentido amplo (produção do ser humano por ele mesmo) implica e compreende a produção de idéias, das representações, da linguagem. [...] Os homens produzem as representações, as ideias, mas são 'os homens reais, ativos'” (LEFEBVRE, 1999b, p. 44). Desse modo, o autor afirma que o conceito de produção é também uma representação, porque abarca as relações sociais através da autorreprodução do ser humano, ser social, espacial e temporal. O conceito de produção, nesse sentido, comporta as representações que interpretam as vivências e as práticas: "Las representaciones circulan, pero en torno a fijezas: las instituciones, los símbolos y arquetipos. Interpretan la vivencia y la práctica: intervienen en ellas sin por ello conorcelas ni dominarlas" (LEFEBVRE, 1983, p. 28). Assim, “[...] las representaciones son productos de la mente humana, de la división social del trabajo. Interpretaciones de la práctica, mutilándola o transponiéndola, se utilizam políticamente” (LEFEBVRE, 1983, p. 29).

Lefebvre (1999b, p. 142) afirma também que "hoje, o espaço inteiro entra na produção como produto através da compra, da venda, da troca de parcelas do espaço", mas que, no entanto, a produção do espaço não é nova, pois sempre foi realizada pelos sujeitos e/ou grupos de determinadas épocas. Assim, o espaço para o autor é criação: "quem cria o espaço cria o que o preenche” (LEFEBVRE, 1999b, p. 146), e na produção do espaço há intencionalidades, há formas de produzir e reproduzir desiguais que dão variadas formas-conteúdos ao espaço produzido, apropriado e dominado. Desse modo, queremos discutir como que a produção do espaço tem seus "meandros", considerados, aqui, a mobilidade, a acessibilidade e a exclusão social. 


\section{Meandros na produção do espaço urbano: mobilidade, acessibilidade e exclusão social}

Para que o espaço urbano seja produzido é necessário a mobilidade: mobilidade de pessoas, mobilidade de objetos, de ações, de representações, de idéias, de mercadorias dentre outros. O espaço urbano é, desse modo, um amálgama de elementos que se movem, interagem e são solidários e contraditórios, porque criam espaços diferenciados, cada qual com sua função, com sua relação social. Neste contexto, compreendemos por mobilidade urbana a "relação social ligada à mudança de lugar, isto é, como o conjunto de modalidades pelas quais os membros de uma sociedade tratam a possibilidade de eles próprios ou outros ocuparem sucessivamente vários lugares" (LÉVY, 2001, p. 1). A mobilidade urbana se liga ao conjunto de possibilidades de um indivíduo, ou de um grupo ocupar vários lugares sucessivamente.

Ainda segundo Lévy (2001), a mobilidade urbana é de grande importância, pois se entende:

[...] como uma relação social de grande riqueza, engendrada por uma realidade que se pode estabelecer como um problema: no espaço das sociedades, a existência de distâncias entre objetos e operadores de todos os tipos cria um risco de separação e de desconexão antinômicas com a interação social. Logo, aparece uma solução: colocar em relação os lugares que engendram essas distâncias (LÉVY, 2001, p. 1).

Segundo Souza (2005, p. 120), “a mobilidade expressa de que forma e por que razões as pessoas se deslocam nas cidades". As pessoas "necessitam" estar em constante movimento. Ir ao trabalho, escola, igreja, clube e às compras tornou-se um componente inerente aos citadinos. Os motivos para os usos dos sistemas de circulação são os mais variados, no entanto boa parte da população se movimenta com mais dificuldade devido às más condições financeiras.

Vasconcellos (2001) especifica que os fatores principais que interferem na mobilidade das pessoas são a renda, o gênero, a idade, a ocupação e o nível educacional. Esses fatores socioeconômicos diferenciam e condicionam as condições de cada pessoa ou grupo social de movimentar-se pelo espaço urbano. Por exemplo, segundo o autor, a mobilidade, em sua maioria, diminui para as pessoas de renda baixa, para as mulheres, para as crianças, para os idosos e para os que exercem funções menos qualificadas no mercado de trabalho. Nesse contexto, a forma do espaço urbano tem importante 
influência na mobilidade das pessoas: "La forma urbana es el marco sobre el que las personas, las mercancías y la información se mueven, de ahí su importancia cuando queremos realizar un estudio sobre movilidad urbana" (GUERRERO, 2003, p. 18).

Para Gaudemar (1977, p. 32), “a mobilidade é introduzida como condição da força de trabalho se sujeitar ao capital e se tornar mercadoria cujo consumo criará valor e, assim, produzirá o capital”. A mobilidade do trabalho reúne duas dimensões: a espacial (horizontal) e a social (vertical). A mobilidade espacial pode ser considerada a capacidade da força de trabalho conquistar vastas extensões. Desse modo "a mobilidade da força de trabalho é, assim, uma característica do trabalhador submetido ao capital e, por essa razão, do modo de produção capitalista. A força de trabalho deve ser móvel, isto é, capaz de manter os locais preparados para o capital" (GAUDEMAR, 1977, p. 33).

Segundo Pereira (2007), a circulação é extremamente essencial para que haja o deslocamento das pessoas até seus locais de trabalho, já que, normalmente, há uma separação entre estes e o local de moradia, bem como das demais atividades necessárias à sua reprodução, o que implica em custos que, muitas vezes, não podem ser pagos, fazendo com que as pessoas busquem outras alternativas, como ir a pé ou de bicicleta. Por isso, a mobilidade dos citadinos é diferenciada também pelo fator renda e o acesso aos diversos meios de transportes.

Assim, as pessoas com menor renda sempre terão que resolver questões básicas relativas à sua reprodução, ou seja, precisam conseguir habitação e emprego, além do deslocamento para realizar essas e outras atividades, geralmente por meio de transporte coletivo. Muitas vezes, moram distante do trabalho e não têm como custear os seus deslocamentos, tendo que sair mais cedo de sua residência e ir a pé ou de bicicleta, e, em muitos casos, precisam percorrer longas distâncias. Uma acessibilidade adequada não faz parte da vida desses segmentos sociais. Desse modo, o espaço urbano é produzido diferenciadamente:

Essas questões correspondem ao fato do espaço urbano ser produzido, reproduzido e apropriado de acordo com os ditames da lógica capitalista e se encontrar cada vez mais dividido e segmentado socioespacialmente. Nesse sentido, a circulação e a mobilidade de pessoas, bens e mercadorias, nesse espaço, dão-se diferentemente, de acordo com os fatores econômicos, políticos e sociais (PEREIRA, 2007, p. 52, [grifos nossos]). 
Como afirma Sposito (1996, p. 71), “a evolução urbana decorre, ela mesma, de um contínuo processo de diferenciação social. [...] Podemos dizer que a diferenciação social tem como condição uma diferenciação espacial, que através dela se expressa”. Através da diferenciação social urbana tem-se uma diferenciação na produção e na materialização do espaço urbano. Com os processos de urbanização e industrialização, Pereira (2007) afirma que a cidade se reestrutura, e a localização das diferentes atividades também se reorganiza de acordo com o uso do solo, com o direcionamento da expansão urbana e com as infraestruturas. Para essa estruturação espacial se constituir, são necessários os meios de transporte, que poderão ser públicos ou privados, de acordo com o poder aquisitivo dos usuários. Tanto a estruturação espacial quanto a ordenação dos meios de transporte público não são tão simples e espontâneas, estando permeadas por interesses diferenciados dos agentes urbanos. Com isso, não há, portanto, uma situação favorável que permita fluir a circulação de maneira adequada, já que há inúmeros problemas nos sistemas de transporte público e uma grande presença do automóvel particular, implicando na mobilidade e acessibilidade de muitas pessoas, principalmente das que possuem uma renda menor.

Lévy (2001) considera que as relações sociais de mobilidade são de diversas modalidades, pode-se "considerar a mobilidade como um sistema de movimentos potenciais, mais ou menos atualizados, que denominaremos virtualidades" (p. 3). Pode-se classificar, segundo o autor, estas virtualidades segundo três categorias: 1) a mobilidade torna-se possível porque existe uma oferta de mobilidade, a acessibilidade; 2) a mobilidade é efetiva porque os seus operadores possuem uma competência de mobilidade; 3) a mobilidade tem sentido porque, no quadro do domínio do espaço, ela entra na composição do capital social dos indivíduos (LÉVY, 2001, p. 3). Nessa perspectiva, a mobilidade dos indivíduos estaria ligada a três elementos: acessibilidade, competência e composição do capital social. Desse modo, “a realização prática da urbanidade passa pela existência de vários lugares tão inter-relacionados quanto possível, a fim de que tudo ocorra como se eles constituíssem um único lugar. [...] A urbanização é, por princípio, portadora de um crescimento das mobilidades intra-urbanas” (LÉVY, 2001, p. 1-2).

De acordo com Souza (2005), a sociedade atual, de certa maneira, impulsiona os cidadãos para uma efetiva reprodução social. De certo modo, boa parte da população está inserida em um ciclo familiar, de estudos, de trabalho e de lazer. As classes sociais expressam a sua forma de reproduzir-se socialmente. Aos que possuem automóvel particular, a mobilidade se 
acentua devido à maior facilidade de atingir os lugares. Assim, a produção do espaço urbano e a mobilidade citadina ocorrem de maneira diferenciada em função das diferentes formas de uso e apropriação das técnicas de transporte e, por extensão, na forma de acesso e uso dos inúmeros lugares.

Como afirma Pereira (2007), na "cidade do automóvel”, os sujeitos que possuem veículo próprio utilizam constantemente esse meio para os deslocamentos em função das suas atividades, mesmo que elas se encontrem a curtas distâncias de sua residência. Esses sujeitos podem residir em áreas mais centrais, como também nas áreas de expansão urbana mais recentes, caracterizadas pelos loteamentos fechados, que se encontram geralmente afastados da malha compacta sendo que, nesse caso, a escolha da área de residência leva em consideração a facilidade de deslocamentos por meio do transporte próprio.

Nas grandes cidades, afirma Santos (1996), as periferias são as materializações de mecanismos de exclusão/diferenciação espacial, tais como: habitações insuficientes e de má qualidade, inexistência de infraestruturas básica, baixa possibilidade de acesso rápido e confortável aos lugares de trabalho, malha viária e equipamento de transporte coletivo deficientes. Também, Souza (2005, p. 26) também considera que "a acessibilidade é o acesso fácil, qualidade do que é acessível”, ou seja, numa perspectiva geográfica, é o melhor e mais rápido acesso a determinado (s) lugar (es), é a capacidade de se ter mobilidade "fluída" para realizar aquilo que se tem disponível em outro (s) lugar (es).

A mobilidade, como um fim a ser obtido por um meio de transporte, varia de acordo com o meio em que ela é realizada. Em alguns casos e situações, podemos nos movimentar, movermo-nos pelo espaço urbano a pé para realizar algumas atividades. Segundo Pereira (2007, p. 69), à medida que a extensão territorial desse espaço se amplia e parte dos equipamentos coletivos ainda permanece centralizada, faz-se necessário o deslocamento por meio de transporte motorizado. Esses meios podem ser públicos e coletivos ou privados e individuais, de acordo com a renda dos usuários, sendo que a oferta, qualidade, eficiência e o tempo de deslocamento entre eles serão bastante diferenciados, implicando em menor grau de acessibilidade dos que dependem do transporte coletivo. Nesse sentido, nem sempre a mobilidade possibilita a acessibilidade pela falta e/ou necessidade de políticas públicas que possibilitem o melhor acesso aos lugares da urbe.

Vasconcellos (2001) salienta que a mobilidade e a acessibilidade são uma relação complexa que permite analisar as diferenciações no uso e na 
produção do espaço urbano. Desse modo, a acessibilidade é entendida como a mobilidade para a realização das necessidades para a reprodução, ou seja, não é simplesmente movimentar-se, mas chegar aos destinos desejados. Nesse sentido, considera-se que há uma conexão entre a oferta do sistema de circulação e a estrutura urbana, e ela refere-se ao modo como o indivíduo pode usar o espaço da cidade.

A mobilidade e a acessibilidade, portanto, estão atreladas ao uso de meios de transporte, considerando a relação espaço-tempo, e se encontram vinculadas à estruturação urbana, que deve ser resultado de políticas e planejamento que direcionam o uso do solo, mas na maior parte dos casos, que resultam sobretudo das iniciativas e interesses dos agentes privados. Para Pereira (2007), o planejamento urbano deve priorizar os interesses coletivos e deve estar associado à estruturação do sistema de transporte público, que proporcione a acessibilidade à cidade, considerando as diferentes áreas onde se localizam as atividades de trabalho, educação, saúde, lazer, comércio e serviços. "Quando a acessibilidade não é favorecida fortalece-se ainda mais a diferenciação socioespacial” (PEREIRA, 2007 p. 71).

Neste contexto, para Raffestin (1993, p. 156), "a distância se refere à interação entre os diferentes locais. Pode ser uma interação política, econômica, social e cultural que resulta de jogos de oferta e de procura, que provém dos indivíduos e/ou grupos”. O transporte coletivo relaciona-se às práticas do exercício de poder econômico, social, cultural, político e geográfico, pois o transporte urbano é planejado (sem neutralidade) e executado dentro de uma atividade que está em acordo com o arranjo socioespacial de uma localidade. Desse modo, "os indivíduos ou grupos ocupam pontos no espaço e se distribuem de acordo com modelos que podem ser aleatórios, regulares ou concentrados. São, em parte, respostas possíveis ao fator distância e ao seu complemento, a acessibilidade” (RAFFESTIN, 1993, p. 158).

Como ressalta Sposito (1996, p. 75), "a diferenciação no interior das cidades, desde a Antigüidade, guarda estreita relação com a privatização do território e a existência de mecanismos econômicos ou políticos controlando o acesso a ele”. E a dificuldade de mobilidade e da acessibilidade precariza ainda mais as condições sociais de vida dos sujeitos, resultando em exclusões sociais, ou, como prefere Martins (1997), na inclusão precária. Para Bourdieu (2001, p.163), a capacidade de dominar o espaço através da mobilidade se dá, sobretudo, pela apropriação de capital material ou simbólico: "O capital permite manter à distância as pessoas e as coisas indesejáveis ao mesmo tempo aproximar-se de pessoas e coisas desejáveis (por causa, 
entre outras coisas, de sua riqueza em capital)”; assim, “o gasto necessário (principalmente o tempo) para apropriar-se deles: a proximidade no espaço físico permite que a proximidade no espaço social produza todos os seus efeitos facilitando ou favorecendo a acumulação de capital social" e, mais precisamente, "permitindo aproveitar continuadamente encontros ao mesmo tempo casuais e previsíveis que garantam a freqüência a lugares bem freqüentados" (BOURDIEU, 2001, p. 164).

Desse modo, a capacidade de se apropriar do espaço econômico e simbólico se dá pelas condições, as quais estão distribuídas entre os indivíduos que ocupam e usam o (s) espaço (s) urbano (s). Sendo assim, uma condição para aproximação de pessoas, de objetos desejáveis, de novas idéias, de novos lugares, pois "a falta de capital intensifica a experiência da finitude: ela prende a um lugar" (BOURDIEU, 2001, p. 164), e prendendo pela falta de capital, precariza os indivíduos (e suas relações) pela "i-mobilidade”, pela não possibilidade de se deslocar, de buscar novas coisas, de ter acesso aos mais diversos lugares da cidade. Enfim, pela exclusão social e espacial.

Segundo Nascimento (1994), o termo exclusão social diz respeito ao ato de excluir, de colocar à margem um determinado grupo social. Refere-se sempre a um processo social de não-reconhecimento do outro, ou de rejeição, ou ainda, intolerância. Dito de outra forma, trata-se de uma representação que tem dificuldades de reconhecer no outro direitos que lhes são próprios. Compreendendo, ademais, a autorepresentação do excluído que, desta forma, ao romper o vínculo societário, desenvolve vínculos comunitários particulares, como forma de sobrevivência social. Sinais de uma coesão social fragmentada ou da multiplicidade de princípios de solidariedade em um mesmo espaço social.

Castells (1979) contribui para o entendimento do processo de exclusão sócioespacial, considerando a existência de cidadãos incluídos e excluídos. O que diferencia o cidadão incluído, pode-se dizer privilegiado, de outro excluído e desprivilegiado é o acesso à renda e a serviços básicos de manutenção da vida urbana. Contudo, o conceito de exclusão social é carregado de significados, e por que não dizer (contra)significados, tem uma dimensão psico-social, pois trata do ressentimento de uma parcela da população que não obtém aquilo que está almejando ou reivindicando.

Santos (1996) também contribuiu para as reflexões acerca do processo de exclusão ao considerar como pobres aqueles que vivem nas cidades e, que não possuem condições de consumir. Esses, ao deparar-se com essa impossibilidade de consumo, sentem-se excluídos, é quase que um sentimento 
psicosocial de exclusão. O que fica claro que os sentidos de exclusão podem ser múltiplos, e a população pobre não possui vários anseios, até porque estamos lhe dando com o espaço urbano como aquele lugar de consumo, produção e construção. Sobre o consumo, Santos (2002, p. 48) afirma que "o consumo é o grande emoliente, produtor ou encorajador de imobilismos".

Santos (2002), afirma ainda que a pobreza e a exclusão aumentaram com a globalização e que os pobres de hoje são excluídos, pois antes, “[...] em um mundo onde o consumo ainda não estava largamente difundido, e o dinheiro ainda não constituía um nexo social obrigatório, a pobreza era menos discriminatória” (p. 49). No espaço urbano, nas últimas décadas, o número de pobres tem aumentando consideravelmente apesar do grande número de políticas públicas no Brasil. Ser pobre é participar de uma situação estrutural, com uma posição relativa inferior dentro da sociedade como um todo (SANTOS, 2002).

Em outra perspectiva, Martins (1997) considera que a palavra exclusão está desmistificando a palavra pobre; a palavra exclusão é confundida, muitas vezes, segundo o autor, com pobreza:

Esta atenção, esta dificuldade - a palavra exclusão indica uma dificuldade, mais que uma certeza - revela uma incerteza no conhecimento que se pode ter a respeito daquilo que constitui o objetivo que se pode ter a respeito daquilo que constitui o objeto da nossa preocupação - a preocupação com os pobres, os marginalizados, os excluídos, os que estão procurando identidade e um lugar aceitável na sociedade. Portanto, a palavra exclusão nos fala, possivelmente, de um lado, da necessidade prática de uma compreensão nova daquilo que, não faz muito, todos chamávamos de pobreza (MARTINS, 1997, p. 28).

Para o autor, o problema da exclusão nasce com a sociedade capitalista "É uma sociedade que tem como lógica própria tudo desenraizar e a todos excluir porque deve ser lançado no mercado. A lógica do sistema capitalista é o mercado, é o movimento, é a circulação” (MARTINS, 1997, p. 30). Desse modo, o sistema capitalista exclui para incluir precariamente, sendo que, a exclusão social seria, portanto, uma inclusão precária: “todos nós, em vários momentos de nossa vida, e de diferentes modos, dolorosos ou não fomos desenraizados e excluídos”. Faz parte da lógica de exclusão, a inclusão, pois “ $a$ sociedade capitalista desenraiza”., exclui, para incluir, inclui de outro modo, segundo sua própria lógica. O problema está justamente nessa inclusão" (MARTINS, 1997, p. 32).

Também, o conceito de exclusão é reforçado, quando o Estado, que deveria dar garantias sociais à população como um todo, nega esse direito, 
exacerbando o sentimento da população atingida por esse desamparo. Devemos considerar que existe exclusão, pois quando Lefebvre (1999b) diz que o espaço urbano torna-se o lugar do encontro das coisas e das pessoas e da troca, somos instigados a fazer a pergunta: quem possui direito a estar nesse espaço? Quem possui condições de realizar essas trocas? Então podemos perceber que tal mobilidade e acesso a esse espaço são limitados. E essa limitação leva a uma tensão no espaço da cidade, em função da diferencialidade de poder entre classes e frações de classes existentes.

\section{Considerações finais}

O espaço urbano é produto e produtor das relações. Produto das relações de mobilidade, de produção, de trabalho, de representações, de modos de vida etc. Produtor, pois à medida que é produzido, transforma as relações dos sujeitos, daqueles que produzem o espaço, daqueles que levam objetos, que levam relações, ideias etc. Ao mesmo tempo em que se produz o espaço, os sujeitos são produzidos por esse espaço. Por isso, a produção do espaço urbano está sempre em processo, nunca é algo acabado, terminado.

Dessa forma, atrelado à produção do espaço urbano está inerente à mobilidade das pessoas. As infraestruturas, que são estruturantes e estruturadas no espaço urbano de maneira diferenciada, determinam a mobilidade que pode propiciar ou não a acessibilidade de determinados grupos, classes e/ou frações de classes a determinados lugares do espaço urbano. A mobilidade urbana permite, portanto, uma acessibilidade rápida e eficaz para determinados lugares no espaço em que se busca chegar, deslocar, enfim, atingir os objetivos da territorialidade ligados à funcionalidade urbana, da produção de mercadorias, do capital etc. No entanto, por outro lado, a mobilidade também propicia a não acessibilidade e/ou a i-mobilidade, isto é, a exclusão social nas relações sociais no espaço urbano.

Desse modo, o espaço urbano é produto de relações desiguais que geram mobilidades e acessibilidades diferenciadas aos lugares. É produtor também porque é estruturado por objetos e ações que atribuem mobilidades e acessibilidades às pessoas de maneira diferenciada. Essa desigualdade e essa não acessibilidade gera, em grande medida, exclusão social pela dificuldade ou não acesso aos inúmeros lugares da cidade impedindo, portanto, o direito à cidade. 
1 Agradeço a leitura atenciosa e as sugestões realizadas pela professora Maria José Martinelli Silva Calixto, do curso de graduação e pós-graduação em Geografia da Universidade Federal da Grande Dourados - UFGD.

\section{Referências}

BOURDIEU, Pierre. Efeitos do lugar. In: BOURDIEU, Pierre (Coord.). A miséria do mundo. 4 ed. Petrópolis: Vozes, 2001, pp.159-175.

CALIXTO, Maria José Martinelli S. As articulações político-ideológicas do poder público no processo de (re)definição da diferenciação sócioespacial. Boletim paulista de Geografia. São Paulo: AGB, No 78, Dez. 2001, p. 77-96.

CARLOS, Ana Fani. Espaço e tempo sociais no cotidiano. In: CARLOS, Ana Fani. O espaço urbano: novos escritos sobre a cidade. São Paulo: Contexto, 2004, p. 59-66.

CASTELLS, Manuel. A questão urbana. Rio de Janeiro: Paz e Terra, 1979, p. 127-153.

CORRÊA, Roberto Lobato. Espaço, um conceito-chave da Geografia. In: CASTRO, Iná Elias de; GOMES, Paulo César da C.; CORRÊA, Roberto Lobato. Geografia: conceitos e temas. Rio de Janeiro: Bertrand Brasil, 1995, p. 15-47.

CORRÊA, Roberto Lobato. Trajetórias geográficas. Rio de Janeiro: Bertrand, 1997.

GAUDEMAR, Jean-Paul de. Mobilidade do trabalho e acumulação do capital. Lisboa: Estampa, 1977.

GUERRERO, Rafael Sergio Porcar. La relación entre estructura urbana y movilidad obligada residencia - trabajo. Teoría, evidencia e implicaciones en el diseño de políticas: el caso de la región metropolitana de Barcelona. 2003. Treball de recerca. Universidad Autónoma de Barcelona, Barcelona.

HARVEY, David. Condição pós-moderna. Uma pesquisa sobre as origens da mudança cultural. São Paulo: Edições Loyola, 1994.

LEFEBVRE, Henri. La Production de l'Espace. Paris : Anthropos, 1974.

A cidade do capital. Rio de janeiro: DP\&A, 1999a.

. A revolução urbana. Belo Horizonte: Ed. UFMG, 1999b.

. La presencia y la ausencia: contribuición a la teoria de las representaciones. México: Fondo de Cultura Económica, 1983.

O direito à cidade. São Paulo: Centauro, 2001.

LÉVY, Jacques. Os novos espaços da mobilidade. Geographia. Rio de Janeiro. Ano III - No 6 Jul-Dez, 2001.

MARTINS, J. S. Exclusão e a nova desigualdade. São Paulo: Paulus, 1997.

NASCIMENTO, Elimar Pinheiro do. Hipóteses Sobre a Nova Exclusão Social: dos excluídos necessários aos excluídos desnecessários. Cad. CRH., Salvador, n.21. p.29-47, jul./dez. 1994.

PEREIRA, Sílvia Regina. Mobilidade espacial e acessibilidade à cidade. Revista OKARA: Geografia em debate, v.1, n.1, p. 1-152, 2007. João Pessoa, PB, DGEOC/CCEN/UFPB. 
RAFFESTIN, Claude. Por uma geografia do poder. São Paulo: Ática, 1993.

SANTOS, Milton et al. Território: globalização e fragmentação. São Paulo: Hucitec, 1996.

A natureza do espaço. 4 ed. São Paulo: Edusp, 2004.

. Por uma outra globalização do pensamento único à consciência universal. São Paulo, Ed. Record, 2002.

. Técnica, espaço, tempo. Globalização e meio técnico-científico informacional. 3 ed. Hucitec: São Paulo, 1997.

SOUSA, Marcos Timóteo Rodrigues. Uma abordagem sobre o problema da mobilidade e acessibilidade do transporte coletivo, o caso do bairro Jardim São João no município de Guarulhos-SP. 2003. Dissertação (Mestrado em Engenharia Civil), Universidade de Campinas, Campinas.

. Mobilidade e acessibilidade no espaço urbano. Revista Sociedade e Natureza, 17(33): 119-129, Dez, 2005.

SPOSITO, Maria Encarnação Beltrão. A urbanização da sociedade: reflexões para um debate sobre novas formas espaciais. In: DAMIANI, A. L. et al (org.). O espaço no fim do século: a nova raridade. São Paulo: Contexto, 1999. p. 83-99.

SPOSITO, Maria Encarnação Beltrão. Reflexões sobre a natureza da segregação espacial nas cidades contemporâneas. Revista de Geografia. Dourados: AGB, 1996, p. 71-85.

VASCONCELLOS, Eduardo Alcântara. Transporte urbano, espaço e equidade: análise das políticas públicas. São Paulo: Annablume, 2001.

Marcos Leandro Mondardo - Mestre em Geografia pela Universidade Federal da Grande Dourados - UFGD. Professor da Universidade Estadual de Mato Grosso do Sul - UEMS.

Recebido para publicação em Março de 2009 Aceito para publicação em Maio de 2009 
